\title{
Appropriateness of low-cost sewerage for African cities: a questionnaire survey of expert opinion
}

\author{
Guy Norman ${ }^{1} \&$ Jonathan Chenoweth ${ }^{2}$ \\ ${ }^{1}$ Robens Centre for Public and Environmental Health, University of Surrey, UK. \\ ${ }^{2}$ Centre for Environmental Strategy, University of Surrey, UK.
}

\section{SUMMARY}

A questionnaire survey was circulated via Internet-based sanitation forums to assess prevailing expert opinion about the appropriateness of low-cost sewerage for African cities. The questionnaire explored opinions about low-cost solids-free sewerage (settled sewerage), low-cost solidstransporting sewerage (simplified sewerage, condominial sewerage), and conventional solidstransporting sewerage. A total of 61 valid responses were obtained: $83 \%$ of respondents considered low-cost sewerage to be "sometimes" or "often" appropriate for lower-income districts of African cities, versus $17 \%$ who considered it "never" or "very rarely" appropriate. In contrast, only $44 \%$ of respondents considered conventional sewerage to be "sometimes" or "often" appropriate. Thus low-cost sewerage is widely viewed as a serious option to be given serious consideration during urban sanitation planning in African contexts. However, most respondents consider it appropriate only in certain specific situations, and many express concern about costs and long-term maintainability. Respondents' comments concerning specific situations in which low-cost sewerage may be appropriate are discussed in detail.

\section{1) INTRODUCTION}

Provision of adequate sanitation remains a major problem for most African cities (WHO/UNICEF, 2004; AMCOW, 2008). However, practitioners and researchers often appear to have widely divergent opinions about the most appropriate solutions to use. One obvious reason for this is that the suitability of different approaches varies according to context: so approaches appropriate for a wealthy, flat city with arid climate will probably not be appropriate for a poor, hilly city with humid climate. Indeed, the most appropriate solutions will often vary from one district of a city to another. A second difficulty is in quantifying cost-effectiveness: in a given context, we may be able to approximately predict the per-household investment costs of diverse options (e.g. "no action", "urine-diverting latrines" or "sewerage"), but it will be very difficult to accurately assess the lifecycle costs and relative benefits of each option. A third difficulty is of interdependence: for example an acceptable system based on pit latrines may require sludge treatment, which in practice will often take place in the treatment facilities used for sewerage wastewater.

The appropriateness of waterborne sewerage for African cities is particularly controversial, with some authors regarding sewerage as fundamentally anti-poor: for example, Allen \& Hoffman (2008) state that "efforts by policymakers and bureaucrats seem to focus on network sewerage and centralized systems that do little to improve sanitation in urban low-income areas". Certainly many previous sewerage projects have performed very poorly, often achieving much lower coverage than planned (Wright, 1997). Sewerage is also widely criticized on environmental grounds: so for example SuSanA (2008) refers to a growing consensus "that conventional approaches -flush toilets connected to centralized wastewater treatment plants that dispose into local waterways- are economically and 
environmentally unsustainable". The situation is further complicated by the existence of various lowcost sewerage solutions, developed most notably in Brazil and in Pakistan. These solutions use technical strategies (such as smaller-diameter pipes, local materials, shallower gradients or less frequent inspection points) and/or socio-organizational strategies (including community financing, community construction and community maintenance) designed to reduce costs, and thus to make sewerage more affordable for poorer communities: for overviews, see Mara (1996); for outcome evaluations, see especially Watson (1995), Vines \& Reed (1991a, 1991b), Zaidi (2001) and Nance \& Ortolano (2007). These low-cost approaches have been in use since the 1980s, but to date have scarcely been piloted -let alone used at scale- in sub-Saharan Africa (see Tayler 2004). Why is this? Are these solutions viewed by sanitation specialists as inappropriate in African contexts, or indeed as inappropriate in general?

These questions are particularly relevant in the wake of the International Year of Sanitation 2008. IYS documentation (UN-Water 2008) notes that "in some poor urban communities, where housing is permanent and livelihoods on the 'up', cheaper forms of sewerage - small diameter pipes, community-based management and maintenance - are practicable and can be connected to the main sewer system". Is this view widely held by sanitation specialists? In particular, can systems of this type be operationally sustainable in African contexts?

With the aim of answering these questions, the present questionnaire study assessed prevailing opinions and attitudes about the appropriateness of low-cost sewerage for low-income districts of African cities. The questionnaire was distributed via Internet forums used by sanitation specialists.

\section{2) METHODS, SCOPE, AND LIMITATIONS}

The questionnaire was written with the explicit aim of assessing opinions and attitudes about lowcost sewerage. Questions about conventional sewerage were also included, for comparative purposes. A PDF copy of the questionnaire is available from the authors on request.

The questionnaire started with a brief definition of terms. Low-cost solids-free sewerage systems (settled sewerage systems, sewered interceptor tank (SIT) systems, small-bore sewerage) are systems in which large solids are settled out in an interceptor tank near the toilet, and only the liquid fraction of the wastewater is piped away. Low-cost solids-transporting systems (simplified or condominial sewerage systems) are reduced-cost systems in which all wastes, including large solids, are piped away, as in conventional sewerage; the systems developed in Brazil and Pakistan are of this type. Conventional sewerage systems are conventional solids-transporting systems, with no specific adaptations for reduced cost. The questionnaire follows this simple three-way classification, though recognizing that other classifications are possible, and in particular that the dividing line between low-cost and conventional solids-transporting systems is not always clear-cut; see also Section 3.2.

The questionnaire was administered within SurveyMonkey (www.surveymonkey.com/Default.aspx), an online tool for creating, distributing and collecting responses from Internet surveys. After piloting, the final version was circulated in January 2009 to several Internet forums (the EcoSanRes group, ecosanres@yahoogroups.com; the Water and San Applied Research group, water-and-san-applied- 
research@jiscmail.ac.uk; the Urban Water Supply and Sanitation Reform group, urbanwater@dgroups.org), and to several closed groups via that group's administrator (the "Sanitation and water management in developing countries" group of the International Water Association; the ATPS [African Technology Policy Studies] network; WATSANET [Water and Sanitation Network in Tanzania]; UWASNET [Uganda Water and Sanitation Network]; the TREND group [Ghana]; the Water and Sanitation Association of Zambia). Note the deliberate inclusion of both EcoSanRes (which we might expect to be relatively "anti-sewerage") and the World Bankrelated Urban Water Supply and Sanitation Reform group (which we might expect to be relatively "pro-sewerage").

The questionnaire was kept online for about 2 months, during which time a total of 105 responses were obtained; of these, 61 (58\%) were classed as valid (i.e. with completion of most questions, and supply of a name and email). Most of the invalid responses consisted simply of an answer to the first question. In what follows, we consider only the 61 valid responses.

Self-reported respondent characteristics $(n=61)$ can be briefly summarized as follows: $25 \%$ sanitation engineers or similar, $21 \%$ academic researchers, $13 \%$ NGO sanitation specialists, $8 \%$ sanitation consultants, $33 \%$ other (Question 24); $28 \%$ from sub-Saharan Africa, $25 \%$ from UK, $48 \%$ from rest of world (Question 23). Four respondents were from South Africa (where low-cost sewerage solutions have been piloted but with little success, for basically political reasons; see e.g. Eslick \& Harrison, 2004). Excluding South Africa and Mauritius, only 11 respondents were currently working in sub-Saharan Africa, and of these only 4 were African nationals. Some potential African respondents may not have a sufficiently good Internet connection to enable completion of an online questionnaire, and in view of this we also distributed text-only versions. The small number of responses from African professionals may also reflect other factors (e.g. infrequent participation in email-administered forums). In addition, the questionnaire was only made available in English, not in French or other relevant languages.

Following analysis of the questionnaire findings, a draft version of this report was sent to 10 selected respondents, all with strong experience of urban sanitation in Africa. The respondents were asked to review the Conclusions section, with the aim of ensuring that the report fairly represented all views expressed in the questionnaire, and accurately summarized majority views.

\section{3) FINDINGS}

\section{1) Summarized findings}

The full questionnaire text and findings (except for respondent names and other identifying details) are available from the authors on request. In what follows, we present a summary of responses (abbreviations: $\mathrm{Q}=$ question, $\mathrm{R}=$ respondent).

Of the 61 respondents, $83 \%$ considered low-cost sewerage to be "sometimes" or "often" appropriate for lower-income districts of African cities; only $17 \%$ considered it "never" or "very rarely" appropriate (Figure 1) (Q1). Thus a clear majority of respondents consider that low-cost sewerage may be a serious option in some contexts. [If we consider the 41 invalid responses rather 
than the 61 valid responses, the percentage considering low-cost sewerage to be "sometimes" or "often" appropriate was somewhat higher (90\%): this suggests that respondents who started but abandoned the questionnaire had broadly similar views, or indeed somewhat more pro-sewerage views, than those eventually included in the analysis.]

By contrast, only $44 \%$ of the 61 respondents considered conventional sewerage to be "sometimes" or "often" appropriate for lower-income districts of African cities, versus $56 \%$ who considered it be "never" or "very rarely" appropriate (Figure 1) (Q7). Nonetheless, $44 \%$ is by no means a negligible proportion, as discussed in Section 3.2.

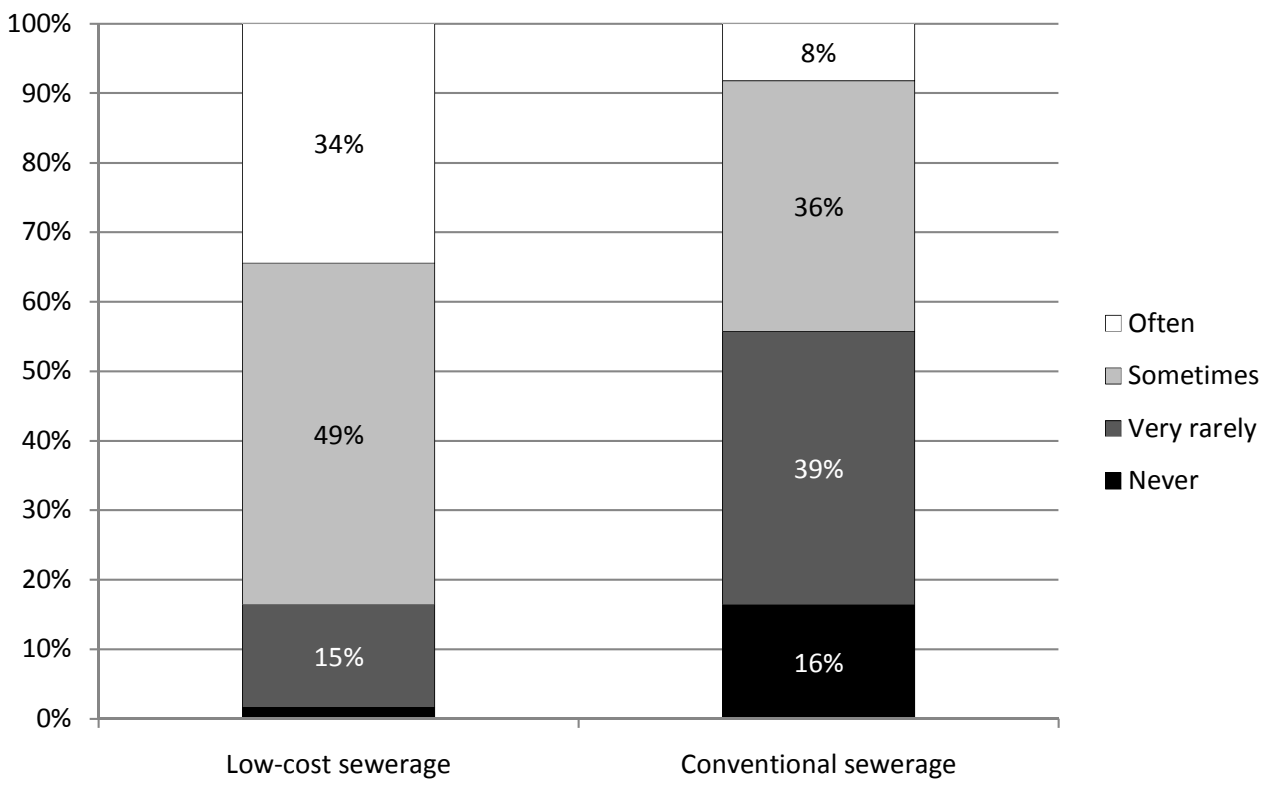

Figure 1. Proportion of respondents $(n=61)$ who considered low-cost sewerage (left) and conventional sewerage (right) to be "never", "very rarely", "sometimes" or "often" appropriate for low-income districts of cities in sub-Saharan Africa.

Evidently, the appropriateness of any sanitation solution will depend on the environmental and sociodemographic characteristics of the city district under consideration. To explore opinions about this, respondents were asked whether they agreed or disagreed with the statements shown in Table 1. Respondents showed some degree of consensus a) that pit latrines are often problematic because of lack of space; b) that pit latrines often cause contamination of water sources; c) that the capital costs of sewerage network extension will be reduced if trunk sewers already exist nearby; d) that low-cost sewerage may be cheaper per capita than on-site solutions in settlements with high population density; e) that low-cost sewerage should be given serious consideration in areas with high water table or regular flooding; and f) that householders themselves will usually prefer waterborne sewerage over onsite systems. Responses to other statements indicate lack of consensus and/or a recognition of context-dependence: thus for example some respondents think low-cost sewerage will tend to negatively impact the region's water resources $(25 \%)$, others that it won't (36\%), and still others that "it depends" (36\%). In additional comments [Q3], several respondents pointed out that it is difficult to generalize about the appropriateness of low-cost sewerage: the authors certainly recognize that this is the case. 
Table 1. Summary of responses to Question 2, in which respondents were asked to agree or disagree with each of statements a-p. A "maybe" option was also offered ("if you're not sure or it depends"). The responses were then scored with 1 for each "agree" response, 0 for each "maybe" response, and - 1 for each "disagree" response; so mean scores close to 1 or -1 indicate consensus. The statements were originally listed in an arbitrary order; here they are listed in order of mean score magnitude. Most statements were rated by all 61 respondents; four were rated by only 60 or 59 .

\begin{tabular}{|c|c|c|c|c|}
\hline STATEMENT & AGREE & MAYBE & DISAGREE & SCORE \\
\hline $\begin{array}{l}\text { a) "In dense urban settlements, plot sizes are often so small that there is no } \\
\text { space to dig new pit latrines." }\end{array}$ & $72 \%$ & $21 \%$ & $7 \%$ & 0.66 \\
\hline $\begin{array}{l}\text { b) "Pit latrines are often a big problem in dense urban areas because they } \\
\text { cause faecal contamination of water sources." }\end{array}$ & $67 \%$ & $26 \%$ & $7 \%$ & 0.61 \\
\hline $\begin{array}{l}\text { c) "If trunk sewers already exist nearby, the capital costs of network extension } \\
\text { will be relatively low." }\end{array}$ & $59 \%$ & $38 \%$ & $3 \%$ & 0.56 \\
\hline $\begin{array}{l}\text { d) "In settlements with high population density, low-cost sewerage may be } \\
\text { cheaper per capita than onsite solutions." }\end{array}$ & $59 \%$ & $36 \%$ & $5 \%$ & 0.54 \\
\hline $\begin{array}{l}\text { e) "Low-cost sewerage should be given serious consideration in areas with } \\
\text { high water-table or regular flooding." }\end{array}$ & $61 \%$ & $25 \%$ & $15 \%$ & 0.46 \\
\hline $\begin{array}{l}\text { f) "Householders will usually prefer waterborne sewerage over onsite } \\
\text { systems." }\end{array}$ & $51 \%$ & $38 \%$ & $12 \%$ & 0.39 \\
\hline $\begin{array}{l}\text { g) "It will probably be difficult to achieve adequate community involvement for } \\
\text { low-cost sewerage projects." }\end{array}$ & $18 \%$ & $30 \%$ & $53 \%$ & -0.34 \\
\hline $\begin{array}{l}\text { h) "Domestic water supply will usually be insufficient (or too intermittent) for } \\
\text { proper function of low-cost sewerage." }\end{array}$ & $50 \%$ & $33 \%$ & $17 \%$ & 0.33 \\
\hline $\begin{array}{l}\text { i) "Low-cost sewerage systems will probably fail because of poor } \\
\text { maintenance." }\end{array}$ & $43 \%$ & $48 \%$ & $10 \%$ & 0.33 \\
\hline $\begin{array}{l}\text { j) "If pit emptying systems are failing severely, low-cost sewerage should be } \\
\text { seriously considered." }\end{array}$ & $48 \%$ & $34 \%$ & $18 \%$ & 0.30 \\
\hline k) "The capital costs of low-cost sewerage systems will invariably be too high." & $14 \%$ & $46 \%$ & $41 \%$ & -0.27 \\
\hline $\begin{array}{l}\text { I) "Low-cost sewerage is only appropriate in communities that produce large } \\
\text { volumes of greywater (sullage)." }\end{array}$ & $27 \%$ & $23 \%$ & $50 \%$ & -0.23 \\
\hline $\begin{array}{l}\text { m) "Waterborne sewerage will probably lead to increased pollution of rivers } \\
\text { and other water bodies." }\end{array}$ & $38 \%$ & $44 \%$ & $18 \%$ & 0.20 \\
\hline $\begin{array}{l}\text { n) "The overall water requirement for low-cost sewerage will be too high, } \\
\text { exacerbating city-level or regional water scarcity." }\end{array}$ & $25 \%$ & $39 \%$ & $36 \%$ & -0.11 \\
\hline $\begin{array}{l}\text { o) "Low-cost sewerage solutions will rarely be pro-poor because of } \\
\text { inadequately secure land tenure." }\end{array}$ & $28 \%$ & $40 \%$ & $33 \%$ & -0.07 \\
\hline $\begin{array}{l}\text { p) "Most householders won't be willing or able to pay for operation and } \\
\text { maintenance of a low-cost sewerage system." }\end{array}$ & $30 \%$ & $46 \%$ & $25 \%$ & 0.05 \\
\hline
\end{tabular}

Several respondents stressed that decisions about the possible introduction of sewerage require detailed context-specific analysis: so for example Respondent 2 (Q12) states a need for "preliminary analysis taking into account a) urban design and constraints, b) rainfall and drainage, c) soil infiltration capacity, d) size of household plots, e) household and communal affordability, and f) alternative onsite solutions including ecosan solutions".

\section{2) Low-cost sewerage versus conventional sewerage}

Before progressing further, we should note a response that queried whether "low-cost sewerage" is a meaningful term. Specifically, Respondent 62 wrote: "when all the costs are added up (toilet, structure, household pipes, township reticulation, outfall sewers and works), there is minimal difference between what is called low-cost and conventional sewerage". This statement perhaps reflects two separate judgements: a) that low-cost sewerage is often dependent on existing or 
required infrastructure (trunk sewers, treatment plants, etc.) that is not taken into account in costings; and b) that many of the cost-reducing features of low-cost sewerage (narrower pipes, community labour, etc.) are false economies in that they may reduce performance and/or increase life-cycle costs. So Respondent 62 states that "Waterborne sewage has minimum gradients for a very good reason, that is to ensure that the solids do not settle out in the pipes. [...] In very dense settlements, where the volume rapidly increases, the gradients can be reduced and thus keep the sewer shallow. Where the sewer is less than $1 \mathrm{~m}$ deep it is possible to build very simple [inspection chambers]; beyond this a manhole that can accommodate a person is required. [...] On why mainline sewers are $150 \mathrm{~mm}$ diameter and [household pipes] $100 \mathrm{~mm}$ diameter there is a very good reason for this. If something large gets into the pipe it will stick in the $100 \mathrm{~mm}$ pipe and the household will have to clear it; if it gets through to the $150 \mathrm{~mm}$ pipe, the chances are it will not block the pipe. For a very minimal capital cost saving, problems are created for the municipality". Replying to this, Respondent 40 notes that there is no fundamental reason why connections should not be $75 \mathrm{~mm}$ diameter (though a lack of suitable sanitary fittings is an obvious obstacle in practice).

In what follows we will use the term "low-cost sewerage" in a deliberately broad sense to refer to systems of household/neighbourhood connection in which efforts have been made to reduce construction costs through application of technical and/or socio-organizational strategies. We note a) that it is possible to build systems that apply some but not all of these strategies; and b) that the application of these strategies will not necessarily be successful in reducing life-cycle costs.

\section{3) Low-cost sewerage: general appropriateness for African cities}

As noted, most respondents consider low-cost sewerage to be an appropriate solution in some situations. However, a significant minority consider it to be very rarely or never appropriate, and many people in the "sometimes appropriate" category consider it to be the correct choice only in very specific situations.

Only one respondent considered that low-cost sewerage can never be an appropriate solution for lower-income districts of African cities, though he noted that it may be an option "for high-and middle-income peri-urban areas" (R61, Q3). Another respondent suggested that low-cost sewerage is "probably unrealistic unless there is significant buy-in from the community, and difficult in cities that are spread widely geographically" (R48, Q5). Other major critiques of sewerage came from ecosan specialists: "You are just talking about sewers - what about the treatment at the end of the pipe?" (R42, Q3); "Sewerage systems not discharging to some sort of treatment system are most likely to be anti-poor and disastrous for the population and environment" (R53, Q12).

More favourable opinions included the following: "I believe there is huge opportunity to reduce costs and still achieve appropriate functionality [...] using reduced standards for construction (particularly depth of burial where appropriate)" (R14, Q5); "[...] in dense urban areas waterborne sewage is the most cost-effective way of transporting excreta and greywater out of the urban area (R62, citing Holden (2008)). 
The most strongly favourable view was expressed by Respondent 60, a leading proponent of lowcost solids-transporting sewerage: "It should be the sanitation system of first choice; use other systems ONLY if shown to be cheaper (this may occur at very low housing/population densities)".

Respondent 26 reports that between 1975 and 2007 he was involved in "planning, construction and post-evaluation of more than 50 sanitation projects in Africa and Asia [...] Often low-cost sewerage was part of the comparison of technical alternatives, but was ruled out in the local decision-making process at least for major cities".

\section{4) Low-cost sewerage: conditions favouring}

A widely cited requirement for low-cost sewerage is of course water supply: "It's obviously impossible to separate the question of low-cost sewerage from water supply [...] I can imagine hypotheticals where low-volume low-cost sewerage is an option to drive the development of water supply, but in practice it's very hard to imagine... the water volumes come first, then the sewerage" (R45, Q4).

Another respondent stressed the importance of poor drainage: "Low-income areas often suffer from drainage problems and it is the flood problems and ponding of water that affect residents during the wet season that are the driver for demand for sewerage" (R9, Q12). In line with this, the authors note that in the PAQPUD sanitation programme in Dakar, low-cost solids-free sewerage is being introduced in areas with impermeable soils.

\subsection{1) Conditions favouring solids-free systems}

The most commonly cited precondition for solids-free systems was that septic tanks should already exist (Q4, Respondents 3, 4, 7, 14, 25, 38). Respondent 14 (Q4) referred to a costing exercise in South Africa which found "that solids-free was cheaper on life-cycle costs over 20 years if the interceptor tanks already existed; [otherwise] conventional sanitation was cheaper". Likewise, Respondent 38 (Q4) stated that "such systems are most applicable where septic tanks already exist [...]: they do not make much sense if the individual tanks need to constructed".

Other respondents commented that solids-free systems may be appropriate in locations with shallow gradients: "bigger cities like Douala will prefer settled sewerage because of its flat topography which may not provide adequate hydraulic gradient for systems without pumps" (R13, Q4); "I think the system does have potential (especially for areas where it is only possible to lay sewers with flat gradients) [...]" (R9, Q4).

Evidently, solids-free systems can work with considerably less water than solids-transporting systems.

\subsection{2) Conditions favouring solids-transporting systems}

Evidently, solids-transporting systems need both more water and a more regular water supply than solids-free systems, as highlighted by several respondents: "[Solids-transporting sewerage] may not 
find a place in sub-Saharan cities in view of the water required to create the much needed push/force between the source point and treatment site" (R25, Q5). Several people highlighted the need for a regular water supply: "Regular water availability is a requirement [for solids-transporting sewerage]" (R10, Q5; see also R43); "While people may be willing to carry water to 'manual' flush on the odd occasion, it's unusual for them to be willing to do this day in day out" (R38, Q5).

Other respondents noted that whether or not solids-transporting sewers can be laid to shallower gradients (one of the central features of low-cost sewerage) "depends on the geography and settlement patterns" (R38, Q12); "A lot depends on [...] the ground slopes and somewhere for the sewers to be connected to or discharge" (R9, Q5). Respondent 62 notes that "To keep sewers shallow the mainlines need to have [a high density of users] at the head of the system and small plots so that the household lines do not run deep".

Respondent 35 (Q5) suggests that the appropriateness of low-cost solids-transporting sewerage is "extremely context-dependent: [you need] lots of water, decent gradients, and organized land management".

\section{5) Low-cost sewerage: conditions disfavouring}

Widely cited obstacles to low-cost sewerage were urban layout and planning constraints: "the main constraint is the nature of unplanned informal settlements in African cities" (R32, Q5); "[sewerage] is not an option for irregular settlements with lack of town planning and unclear ownership of land, [but is a] good option for regular developed low-cost housing schemes with complete infrastructure as part of a project" (R26, Q5; see also R2).

This view that sewerage is only appropriate in new-built settlements is certainly not shared by many proponents of low-cost sewerage, and cannot be easily squared with views expressed by other respondents: "If population density is high enough, there is simply insufficient space for pit latrines and for subsurface infiltration of liquids, so sewerage may be the only feasible choice" (R20, Q5).

Another widely perceived problem with low-cost sewerage is the difficulty of achieving effective community maintenance (a typical part of the "low-cost" package). Respondent 45 (Q3) suggested that "making a sewerage system dependent on decentralized maintenance may be a devil's bargain. Counting on the householder to do the right thing will probably work for most households, but you only need a few to screw it up". Another respondent (R14, who was personally involved in the eThekwini low-cost sewerage pilots; see Eslick \& Harrison, 2004) states that "In South Africa under the current political dispensation community-based sewerage is very difficult to achieve [...]; an appropriate system in the current South African political climate should be based on institutional ownership and maintenance rather than community based" (Q5). However, another South African (R22) suggests that low-cost sewerage is a "promising approach provided community are prepared to operate and maintain systems". Respondent 8 (Q3) suggests that "people have to be involved in construction and O\&M to give them a feeling of responsibility and avoid any misuse". 


\subsection{1) Problems with low-cost solids-free systems}

The most commonly cited specific concern with solids-free systems is the need for desludging of the onsite interceptor tanks: "With settled sewerage you have the same faecal sludge management challenges that we see with on-site systems [...] Once we can solve sludge management then settled sewerage begins to look viable where there is suitable water supply" (R6, Q4; see similar comments from Respondents 9, 22, 25, 26, 32, and 35). Some respondents queried whether solids-free sewerage can ever be justified: "There is a contradiction when people propose solids-free sewerage where emptying of on-site systems has failed" (R40, Q4; see also Respondent 20, Q4). One respondent suggested that solids-free systems "can only work [if tankers can reach septic tanks], so for very high-density areas with few official roads it is not an option" (R11, Q4).

However, another respondent notes that "there is some experience of systems with interceptor tanks operating for long periods in African conditions" (R43, Q4). This is in reference to the small solidsfree sewerage systems examined by Vines \& Reed (1991a, b) in Zambia, which "continue to function more or less adequately despite the almost complete lack of maintenance and the fact that the interceptor tanks have been full of grit for many years" (Tayler, 2004). In this respondent's opinion "solids-free systems are probably more robust [than solids-transporting systems]" (R43, Q5).

\subsection{2) Problems with low-cost solids-transporting systems}

The most commonly cited specific concern with low-cost solids-transporting systems is maintenance: "Maintenance costs may be too high for sustainable operations" (R10, Q5); "Condominial sewerage requires a lot of [...] sharing of social responsibility [...] Not all African settlements are prepared for such responsibilities" (R31, Q5); "There are likely to be maintenance problems since it is very hard to keep all extraneous solids out of sewers" (R43, Q5). One respondent notes that the risk of blockages is increased in low-income "wiper" communities, due to a tendency to use cheap cleansing materials like newspaper (R38, Q5). [In Africa, "wiper" communities are typically Christian, while Muslims are generally "washers", i.e. use water for anal cleansing.]

Respondent 43 (Q5) suggests that "Perhaps [solids-transporting] sewerage will work better in conjunction with community toilets, where a higher flow can be achieved, but I don't think that there is hard evidence on this".

\section{6) Low-cost sewerage: strategies for improving outcome}

Several respondents note that, if sewerage is selected as an appropriate option, then it must be integrated into broader systems for urban design and planning. Other respondents stressed the importance of high connection rates in sewered areas: "Sewer connections should be compulsory in reach of sewers, otherwise [there will be] underutilisation and clogging" (R26, Q3). Likewise Respondent 29 reports from Brazil that "Most households here use septic tanks. When the water company implements a sewage system, many will not disconnect the septic tank and connect to the sewer instead, as the income is too low to afford the extra monthly expense. This makes the system more expensive (per capita) for those who do connect... it would thus make sense to make 
implementation of sewerage in a neighbourhood a democratically taken decision, but when decided for installation, ALL should adhere".

\section{7) Low-cost sewerage and wastewater as resource}

Question 12 asked respondents to consider diverse other aspects of sewerage appropriateness and pro-poorness, and many commented on wastewater reuse: "Wastewater must be seen as resource, then the whole approach and the relevance of the choices changes"(R7, Q12); "Re-use of sludge from conventional treatment works as compost [can be considered]" (R22, Q12); "Re-use for agriculture is promising but requires the wastewater to be treated" (R4, Q12); "Irrigation with nutrient rich water can be a major benefit for poor communities - even aquifer recharge with proper management should be considered" (R52, Q12; see also R9, R25, R26).

Other respondents mentioned the possibility of biogas generation: "Biogas production from centrally collected wastewater may be an option" (R17, Q5; see also R11). However, a wastewater-to-energy expert (R29) suggests that "it will hardly be worth the effort to digest the sewage for energy production [...], so the treatment just costs money [...]".

\section{8) Systems for sewerage management and maintenance}

Question 13 listed various strategies for improving management and maintenance, and asked respondents to rank them from most to least important. Many respondents considered that a major priority is improved governance at the national or municipal levels. Conversely, many respondents considered increased state and/or donor investment in infrastructures to be a low priority.

Some respondents highlighted different concerns: "The list [in Question 13] missed the most essential aspects: a) Tariffs and cost-recovery systems - essential for improved maintenance; b) Improved communications with users - prior to design and construction; c) Assessment of willingness to pay for improved services - i.e. demand assessment; d) Promotion of improved sanitation - so people know why they should pay and are able to value the services; e) Willingness of users to put pressure on the utility to ensure better operations and maintenance (not tolerating dysfunctional services)... and many more" (R38, Q14). Another respondent (R10) noted that "legal and regulatory frameworks may need revision to allow for effective management of low-cost sewerage systems".

The importance of tariffing and cost-recovery was mentioned by several other respondents: "[Who pays capital costs is debatable], but users must pay O\&M, or the next time there's a budget crisis, sewage will spill everywhere; [there is a need for] honest accounting, estimation and collection of maintenance costs from consumers!" (R45, Q14); "User charges (tariffs) need to be sufficient to finance operational costs including capital maintenance" (R57, Q14). Respondent 57 (Q12) suggests that the sewerage charge needs to be linked to water consumption (typically lower among lowerincome users): "fixed charges for sewerage will invariably be anti-poor".

Some respondents mentioned patronage and corruption: "Infrastructure provision and management in general should be independent of political interference, similar to the legal system" (R14, Q14); "[If 
corruption is a problem], state involvement may lead to unnecessarily big investments (more possibility to deviate money)..." (respondent code withheld).

One respondent suggested that the key problem in African cities is the "very poor knowledge base!" (R61, Q14).

Table 2. Summary of responses to Question 13, in which respondents were asked to rank measures a-g (for improving sewerage maintenance and management) from most important to least important. Only partial results are shown here: for example, measure (a) was rated as most important by $37 \%$ of respondents, as least important by $7 \%$, and in an intermediate category by the remaining $56 \%$. The statements were originally listed in an arbitrary order; here they are listed in order of rating average (rating 1-6, least important - most important).

\begin{tabular}{|c|c|c|c|}
\hline MEASURE & $\begin{array}{l}\text { MOST } \\
\text { IMPORTANT }\end{array}$ & $\begin{array}{l}\text { LEAST } \\
\text { IMPORTANT }\end{array}$ & $\begin{array}{l}\text { RATING } \\
\text { AVERAGE }\end{array}$ \\
\hline a) Improved governance at the national or municipal levels & $37 \%$ & $7 \%$ & 4.51 \\
\hline b) Improved training and knowledge transfer for sanitation professionals & $15 \%$ & $7 \%$ & 3.73 \\
\hline c) Increased state and/or donor investment in system management and/or maintenance & $15 \%$ & $15 \%$ & 3.69 \\
\hline d) Greater community involvement in local sewerage maintenance & $13 \%$ & $11 \%$ & 3.47 \\
\hline e) Better rewards and career prospects for sanitation professionals & $17 \%$ & $17 \%$ & 3.46 \\
\hline f) Increased private sector involvement in sewerage construction and/or management & $0 \%$ & $15 \%$ & 3.15 \\
\hline g) Increased state and/or donor investment in infrastructures & $15 \%$ & $31 \%$ & 2.97 \\
\hline
\end{tabular}




\section{4) CONCLUSIONS}

This article does not pretend to be a consensus statement on the appropriateness of sewerage for poorer districts of African cities, or to offer exhaustive consideration of the different circumstances in which low-cost sewerage solutions might be appropriate. Rather, it has aimed to be a neutral exploration of the diversity of opinions of practitioners and researchers involved in urban sanitation in Africa. This said, the following tentative conclusions can be drawn:

1) Piped sewerage may in some situations be an appropriate sanitation solution for lower-income districts of African cities, provided that long-term management and financing can be guaranteed: in other words, it is a serious option that should be given serious consideration alongside the diverse other possible solutions.

2) Nevertheless, for many city districts, other strategies (e.g. household or communal latrines in conjunction with a well-designed and properly financed system for management of the wet or dry faecal waste) may be more appropriate and pro-poor, at least as the first step in improving sanitation. [Here we note significant disagreement among the 10 respondents who reviewed these conclusions: some considered that onsite solutions are likely to be appropriate in most contexts; others that onsite solutions are frequently problematic, so that sewerage will often be appropriate.]

3) Many respondents stress the importance of effluent discharge: wastewater removed from a sewered district must be disposed of or re-used appropriately, ideally after efficient wastewater treatment, and in any case in such a way as to avoid significant negative health and environmental impacts.

4) Sanitation planning at the city or district level should of course be a context-specific process taking into account a very wide range of local determinants that may include (but that are not restricted to) urban layout, vehicle access, rainfall and drainage characteristics, soil infiltration capacity, greywater production, anal cleansing materials, plot sizes, slopes, presence of existing infrastructure, institutional capacity, funding constraints, willingness to pay, and user preferences and cultural attitudes.

5) Factors that are probably prerequisites for low-cost sewerage (whether solids-free or solidstransporting) are a) household-level piped water supply (though see Conclusion 6); and b) a reasonably high level of social cohesion and stability within the district concerned, at least if community management of the system is envisaged.

6) The need for piped water and stable tenure means that low-cost sewerage will generally not be judged suitable for very poor settlements; however, sewerage systems draining communal toilets, or radical slum development solutions including sewerage (together with other interventions such as tenure securization, water supply and road paving), should not be ruled out.

7) Many respondents note that sewerage may be particularly appropriate in districts that have greywater drainage problems, and/or high water table or frequent flooding. Indeed, several 
respondents suggest that greywater production is the key determinant of whether or not sewerage is the appropriate solution.

8) Factors that may argue specifically in favour of low-cost solids-free sewerage include a) widespread existing use of septic tanks; and b) flat topography (i.e. topography that does not facilitate the steeper piper gradients required for solids-transporting sewerage). Many respondents note that there will be a continued need for sludge removal.

9) Factors that may argue specifically in favour of low-cost solids-transporting sewerage (or indeed conventional solids-transporting sewerage) include a) very high population densities; and b) a regular household water supply. Many respondents are concerned about maintenance problems arising from low-cost construction and community management; however, some argue that these are often no worse than the problems arising with onsite systems.

10) Many respondents note the critical importance with any sewerage system of correct setting of user tariffs, and of effective institutional systems for tariff collection.

One particular comment, from Respondent R6, is in our view worth highlighting: "What is needed is a flexible planning approach which allows investments in trunk services (which may be trunk sewers or FSM) to be linked to communities as they develop local solutions (usually with assistance, as urban sanitation is complex to organise). Thus in one city you might have household-level on-site services, shared on-site services, low-cost sewers linked to trunk sewers, low-cost sewers linked to shared septic tanks, etc., etc. The main constraint is inflexible standards based around technical inputs rather than around performance outcomes". This view implies that a city's sewered and nonsewered sanitation systems should be under the same management: unfortunately, this is rarely the case.

Finally, we conclude by recognizing that a study of this type cannot hope to supply black-and-white answers. However, we hope that this report will be of some interest, and that it may encourage readers to question their views, and to consider how those views might be empirically tested.

\section{ACKNOWLEDGEMENTS}

The authors thank Steve Pedley and Kathy Pond for comments on early versions of the questionnaire; Aidan Cronin, Duncan Mara and Brian Reed for piloting and commenting on the nearfinal version; and the 10 experts who commented on the draft conclusions of this report, namely Rasheed Abiodun Ayeni, Marc Boncz, Jeff Broome, Barbara Evans, John Harrison, Peter Hawkins, Richard Holden, Stephen Hugman, Jonathan Parkinson and Kevin Tayler. 


\section{REFERENCES}

Allen, A. \& Hoffmann, P. (2008) Moving down the ladder: Governance and sanitation that works for the urban poor. Paper presented at the IRC Symposium on Urban Sanitation, November 2008, The Netherlands.

AMCOW [African Ministers' Council on Water] (2008) Can Africa Afford to Miss the Sanitation MDG Target? A Review of the Sanitation and Hygiene Status in 32 Countries. AMCOW, African Development Bank (AfDB), and the World Bank Water and Sanitation Program (WSP).

Eslick, P. \& Harrison, J. (2004) A Summary of Lessons and Experiences from the Ethekwini Pilot Shallow Sewer Study. Report Number TT 225/04, Water Research Commission, South Africa.

Holden, R. (2008) Urban sanitation technologies: the challenges of reaching the urban poor. Paper presented at the IRC Symposium "Sanitation for the Urban Poor", Delft, The Netherlands, 19-21 November 2008.

Mara, D. (1996) Low-Cost Sewerage. John Wiley \& Sons, Chichester, UK.

Nance, E. \& Ortolano, L. (2007) Community participation in urban sanitation. Experiences in northeastern Brazil. Journal of Planning Education and Research 26: 284-300.

Vines, M. \& Reed, R. (1991a) Evaluation of Sewered Aqua Privies in Kabushi, Ndola, Zambia. WEDC, Loughborough University, UK.

Vines, M. \& Reed, R. (1991b) Evaluation of Sewered Aqua Privies in Matero, Lusaka, Zambia. WEDC, Loughborough University, UK.

SuSanA [Sustainable Sanitation Alliance] (2008) Planning for sustainable sanitation. Version 1.1 (October 2008). Published online.

Tayler, K. (2004) Notes on the provision of low-cost sewerage in the context of Africa. Unpublished consultancy report.

UN-Water (2008) Tackling a global crisis: International Year of Sanitation 2008. Available online at http://esa.un.org/iys/index.shtml.

WHO/UNICEF (2006). Meeting the MDG Drinking Water and Sanitation Target: A Mid-term Assessment of Progress. World Health Organization, Geneva, Switzerland.

Wright, A.M. (1997) Toward a strategic sanitation approach: improving the sustainability of urban sanitation in developing countries, UNDP-World Bank Water and Sanitation Program, Washington, D.C.

Zaidi, A. (2001) From the lane to the city: the impact of the Orangi Pilot Project's low cost sanitation model. WaterAid, London. 